\title{
A ARTE NO PROCESSO EDUCACIONAL DA REDE PÚBLICA: ANÁLISE DE POSSÍVEIS CONTRIBUIÇÕES DA PEDAGOGIA WALDORF PARA A ARTE- EDUCAÇÃO
}

\author{
Gabriela Muniz Cardoso \\ Ronaldo Záphasi ${ }^{\mathrm{ii}}$
}

\begin{abstract}
Resumo: Este artigo reflete sobre o uso da arte no processo educacional das escolas públicas e suas dificuldades, buscando compreender se a pedagogia Waldorf, através do pensamento de Rudolf Steiner, pode contribuir para uma melhoria no ensino de arte. O artigo faz um levantamento histórico do estado da arte da atual educação brasileira na arte-educação, abordando pesquisadores como Ana Mae Barbosa e João Francisco Duarte Jr. entre outros, para compreender aspectos históricos sobre a desvalorização do campo e dos estudos em artes, apontamentos sobre a precarização do ensino público e algumas visões de ensino que utilizam a arte no processo educacional.
\end{abstract}

Palavras-chave: Arte; Educação; Escola pública; Pedagogia Waldorf.

\section{ART IN THE PUBLIC NETWORK'S EDUCATIONAL PROCESS: ANALYSIS OF POSSIBLE CONTRIBUTIONS FROM WALDORF PEDAGOGY TO ART- EDUCATION}

\begin{abstract}
This article reflects on the use of art in the educational process of public schools and their difficulties,seeking to understand whether Waldorf Pedagogy, through the thinking of Rudolf Steiner, can contribute to an improvement in the teaching of art. The article makes a historical survey of the state of the art of current Brazilian education in arteducation, addressing researchers such as Ana Mae Barbosa e João Francisco Duarte Jr., among others, to understand historical aspects about the devaluation of the field and studies in the arts notes on the precariousness of public education and some teaching visions that use art in the educational process.
\end{abstract}

Keywords: Art; Education; Public school; Waldorf Pedagogy.

\section{A arte nas escolas}

O ensino das artes nas escolas vêm sendo uma obrigatoriedade há muitos anos. Porém, tal obrigação sofreu modificações no decorrer da sua história. No início, em 1816, com a chegada de Dom João VI ao Rio de Janeiro, foi implantado o ensino de artes nas escolas seguindo o modelo europeu, através da criação da Academia Real de Ciências, Artes e Ofícios. Esse modelo, baseado na estética do neoclássico desde seu nascimento, tornou-se uma arte burguesa. $\mathrm{O}$ ensino das artes regradas buscava a perfeição estética do estilo neoclássico. 
Voltada para o desenho geométrico que acabara por desenvolver dois tipos de estudante: artistas e artífices. O que revela o artigo 77 do título X da Legislação de 1855.

Haverá sempre nestas três aulas duas espécies de alunos: os artistas e os artífices, os que se dedicam às Belas-Artes e os que professam as Artes Mecânicas. Os alunos desta segunda espécie terão um livro próprio de matrícula, no qual se declarará a profissão que seguem, para que os professores o saibam e possam dirigir os seus estudos convenientemente. (BRASIL, 1855, p. 414)

A burguesia na academia real estudava as Belas Artes, as outras pessoas eram dirigidas às artes mecânicas de acordo com a profissão que seguiam ou eram destinadas a seguir, tornando assim o ensino das artes ambíguo. Se não fosse elitizado, seria mecanizado como base para ensinos técnicos.

Mais tarde, apesar da agitação das manifestações da Semana de $22^{\text {iii }}$, o ensino das artes manteve suas tendências tradicionais. É somente em 1948, quando são propostas atividades que realmente visam a auto expressão de estudantes através da arte, que há a fundação da Escolinha de Arte ${ }^{\mathrm{iv}}$, no Rio de Janeiro.

A Arte, que antes era pouco reconhecida como matéria, hoje está cada vez mais exercendo seu verdadeiro papel, que além de ensinar, visa também humanizar seus alunos e alunas. O componente curricular do ensino fundamental vigente no Brasil está focado nas linguagens das artes visuais, dança, música e teatro. A elas estão articuladas à pratica de criar, ler, produzir, construir, exteriorizar e refletir sobre formas artísticas visando como objetivo principal a manifestação de formas de expressão, interação crítica e respeito às diversidades culturais (BRASIL, 2018).

Diante dos problemas atuais do Brasil tais como: violência, desigualdade e desemprego; a educação, sobretudo artística, deve ser uma base para a solução e melhoria da sociedade. Muito se fala do desenvolvimento do ser humano, da sua inteligência, de uma melhoria na educação, mas pouco tem se investido na área.

A Constituição Federal do Brasil de 1988, onde estão assegurados os direitos de todos e todas, prevê em seu Artigo 227 que crianças, adolescentes e jovens têm direitos como educação, cultura, respeito, liberdade, além de livrá-los de toda forma de discriminação, exploração, violência, opressão.

É dever da família, da sociedade e do Estado assegurar à criança, ao adolescente e ao jovem, com absoluta prioridade, o direito à vida, à saúde, à alimentação, à educação, ao lazer, à profissionalização, à cultura, à dignidade, ao respeito, à liberdade e à convivência familiar e comunitária, além de 
colocá-los a salvo de toda forma de negligência, discriminação, exploração, violência, crueldade e opressão. (BRASIL, 1988, p. 132)

Diante da Constituição Brasileira ficam concretos os deveres do Estado, principalmente em proporcionar a essas pessoas uma formação completa e humanizada, livre de qualquer tipo de discriminação, violência ou outros tipos de ações que possam influenciar negativamente no seu desenvolvimento. Na educação, muitas vezes as famílias dependem dessa oferta do Estado para colocarem suas crianças na escola, então cabe a Ele ofertar esse ensino de qualidade.

Além dos deveres com a educação, ficam assegurados também aqueles para a cultura. A Constituição, em seu Artigo 215 diz que: “O Estado garantirá a todos o pleno exercício dos direitos culturais e acesso às fontes da cultura nacional, e apoiará e incentivará a valorização e a difusão das manifestações culturais" (BRASIL, 1988, p. 126).

Em "A arte como processo na educação" (1981) as autoras e os autores apontam que "nosso sistema educativo é, em quase toda sua totalidade, muito condicionador e isola formas de ser e de pensar como se não fossem elas móveis e flutuantes como nossas próprias estruturas mentais” (MÄDER et al,1981, p. 13). Considerando a data de publicação do livro e o relato do trecho apresentado, pode-se analisar como a educação era mecanicista e conservadora, ignorando muitas vezes a ideia de formação de seres pensantes e não robotizados.

Uma diferente forma de ensino através das artes foi idealizada por Rudolf Steiner no início do século XX: a Pedagogia Waldorf. Esta baseia-se em um olhar aprofundado do "ser criança” e das condições necessárias para seu desenvolvimento. Apoia-se na Antroposofia que "enfoca o ser humano sob um ângulo mais amplo, embora seu raciocínio e seus métodos não deixem de ter o mesmo rigor cientifico" (LANZ, 1986, p. 13).

Para a Antroposofia, o ser humano constitui-se de alma e espírito - onde relaciona-se o sentir e o pensar. Embora existentes no ser humano desde seu nascimento, cada um destes se desenvolve a cada sete anos - denominados setênios - e pode ser observado durante toda a vida. A educação por sua vez limita-se aos primeiros vinte e um anos de vida (três primeiros setênios).

Embora ao decorrer dos anos tenham surgido várias visões e formas de ensino, infelizmente algumas escolas públicas ainda apresentam um perfil conservador, demonstrando que a realidade atual não mudou tanto quanto poderia.

Atualmente, em 2020, a pandemia de coronavírus (COVID-19) afetou todo o mundo, em todas as esferas. A solução para a área educacional, por exemplo, inicialmente foi o recesso, mas com a percepção da grandiosidade do novo vírus instalou-se um novo, porém já conhecido, 
método de ensino: o ensino remoto, também chamado de EAD (Ensino a Distância). Burocraticamente o problema foi solucionado, mas na realidade só fez transparecer e potencializar as dificuldades que a educação sempre enfrentou.

Uma nota técnica emitida pelo Todos Pela Educação (TPE) aponta que

Para enfrentar o risco da ampliação de desigualdades, ao lançar mão de estratégias de ensino a distância, é preciso entender que a disposição de recursos tecnológicos é heterogênea entre os alunos e que aqueles que já têm desempenho acadêmico melhor tendem a se beneficiar mais das soluções tecnológicas. (TODOS PELA EDUCAÇÃO, 2020, p. 9)

Para isso é necessário avaliar os recursos tecnológicos que já estão à disposição das alunas e dos alunos, e considerar as diferenças sociais no Brasil que existem não só entre redes de ensino pública e privada, mas também entre estudantes da mesma rede, escola e até mesmo, sala de aula.

A função da escola não pode ser somente alfabetizadora. Sua função não se restringe somente a ensinar, ela é ampla e profunda, ou seja, deve instigar a criticidade e o compromisso em relação à aprendizagem. Além de promover a formação física, intelectual e moral, é designada também a missão de promover a integração de estudantes na comunidade, fornecendo-lhe todos os elementos necessários para seu progresso individual e social. E como a figura acima mostra, os efeitos da pandemia são maiores no ensino de artes, sobretudo pela falta do contato humano entre professor(a) e alunas e alunos, impactando na aprendizagem de todas as crianças.

\section{Problemas enfrentados}

Um dos problemas enfrentados é o preconceito com o universo da arte no processo de ensino. A discriminação do estudo da arte, no Brasil, advém do século XIX desde influências do pensamento de Bonaparte ${ }^{\mathrm{v}}$, líder francês que ainda estava no poder francês, pois sua posição política,

[...] foi uma das influências na configuração do preconceito contra o ensino da arte no Brasil. Acrescente-se a ele o despeito dos portugueses, que não tinham ainda uma Academia de Arte de tão alto nível quanto a projetada por Lebreton $^{\mathrm{vi}}$ para o Brasil. (BARBOSA, 1978, p. 18) 
Além disso, um preconceito estético também iria se instaurar na época. Os membros da Missão $^{\text {vii }}$, de orientação neoclássica, destoaram de artistas locais que produziam obras de estilo barroco. Estes artistas, por serem humildes, populares e mestiços, eram vistos como artesãos e não como artistas. $\mathrm{O}$ estudo da arte então passou a ser feito na Europa, elitizando a arte e tomando-a a partir do academicismo neoclássico, como aponta Barbosa,

Afastando-se a arte do contato popular, reservando-a para the happy few ${ }^{\text {viii }} \mathrm{e}$ os talentosos, concorria-se, assim, para alimentar um dos preconceitos contra a arte até hoje acentuada em nossa sociedade, a ideia de arte como uma atividade supérflua, babado, um acessório da Cultura. (BARBOSA, 1978, p. 20)

A partir disso, torna-se valorizado a arte da burguesia em detrimento da arte popular. Isso permanece até a atualidade, onde enaltecem-se as obras de museus e desprezam-se artistas de rua e artistas populares, ao valorizar as técnicas e deixar de lado a emotividade que a arte pode transmitir, o que, de certa forma, deixa vestígios na própria educação. É quando retomamos os fundamentos do desenho geométrico, abordado anteriormente, transmitindo técnicas e não permitindo a expressão através da arte. Aqui, podemos enfatizar uma crítica não à técnica, e sim à técnica acima da expressão. Estes dois aspectos juntos (técnica e expressão) criam a harmonia do ensino das artes. A aluna e o aluno tendo acesso às diferentes técnicas das diferentes vertentes artísticas poderão escolher qual the agrada e qual trabalhar para se expressar. A técnica isolada da livre expressão tornará a arte academicista, buscando a perfeição, que não deveria ser o objetivo principal e que nem sempre pode ser alcançada devido a fatores como a não predileção às artes, tempo, espaço e material de estudo, entre outros fatores. E a expressão sem a técnica é o caos.

O problema que encontramos, além da desvalorização do conteúdo artístico em nossa sociedade, é da limitação dele dentro do ambiente educacional. O que encontramos nas escolas públicas brasileiras é uma restrição de conteúdo, materiais, espaços e muitas vezes de oportunidades que impedem professores e professoras de atuarem em sua área. Como podemos então, dentro dessa realidade, trabalhar o ensino das artes considerando sua importância no processo educacional?

Docentes, principalmente de escola pública, possuem uma jornada de trabalhado de 40 horas semanais ou mais, possivelmente devido à falta de profissionais. Isso faz com que a comunidade docente de uma escola pública atue em mais de um turno ou mesmo em mais de uma escola, reflexo também da necessidade do aumento de rendimentos (BRASIL, 2004, p. 41). 
Essa dupla ou tripla jornada de trabalho compromete o desempenho do corpo docente, pois, além desta, ocorrem outras atividades que exigem tempo adicional: planejamento das atividades ministradas, disponibilidade para fornecer atendimento ao corpo discente e atividades administrativas relacionadas à escola.

Além do despreparo, do estudo vago, o incentivo nessa área também é afetado. Docentes que atuam na educação infantil ganham, em média, $R \$ 423$. Docentes que lecionam em turmas de $1^{\mathrm{a}}$ a $4^{\mathrm{a}}$ série recebem $\mathrm{R} \$ 462$ e de $5^{\mathrm{a}}$ a $8^{\mathrm{a}}, \mathrm{R} \$ 600$. Já docentes que atuam no nível médio ganham, em média, R 866 (BRASIL, 2004, p. 33). Este estudo realizado pelo INEP, em 2002, demonstra problemas na infraestrutura das escolas. Em média, 32,5\% das escolas na área urbana possuem acesso à internet, enquanto que na rural o percentual cai para apenas $2 \%$. Em relação à biblioteca, o acesso das escolas é de 63,2\% na área urbana e 17,5\% na rural. Laboratórios de informática e de ciências também são precários sendo $31 \%$ e 23,3\% respectivamente na área urbana e $2,8 \%$ e 2,6\% respectivamente na rural. A quadra de esportes também não fica de fora dessas porcentagens assustadoras sendo $60 \%$ na área urbana e 13,8\% na rural. Diante dessa situação calamitosa, como fica o ensino de artes?

Observamos que não há registro de pesquisa quantitativa sobre o "estado da arte" do ensino de arte nas escolas públicas. Assim, não encontramos pesquisas com dados específicos e concretos como os acima citados. Esse fato somente afirma o descaso com o campo das artes e seu ensino, por não haver tanta importância em relação à infraestrutura, ao investimento ou ao salário de docentes da área.

Desse modo, a livre expressão está continuamente sendo delimitada e pouco se investe em cultura e na pesquisa das artes. Muitas melhorias são necessárias para que se possa cumprir o que designa a constituição. Mas, enquanto houver a discriminação com as artes e a ignorância da educação, a falta de recursos, seguiremos formando pessoas robotizadas, formatadas e pouco sensíveis. Para o mercado de trabalho serão mão de obra barata. Mas, no desenvolvimento de nossa pesquisa, encontramos na pedagogia Waldorf uma possibilidade de descobrir outros caminhos para o ensino de arte na escola pública.

\section{A importância da arte na aprendizagem}

Desde que nascemos a arte está presente em nossas vidas, os primeiros movimentos possíveis transformam-se em expressão daquilo que ainda não consegue ser dito. Os primeiros passos dados, com um estímulo musical do agrado, tornam-se uma dança. A mais primitiva Revista Interinstitucional Artes de Educar. Rio de Janeiro, V. 7, N. 1 - pág. 670-685 janeiroabril de 2021: "Pedagogias Vitais: Corpo, Desejo e Educação" DOI: 10.12957/riae.2021.55358 


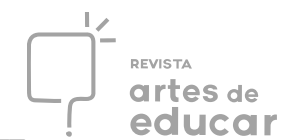

tentativa de fala pode-se tornar uma cantoria. Ao primeiro movimento possível de se segurar um lápis, giz de cera ou qualquer coisa que seja colorida pode virar uma pintura - mesmo que a tela seja uma parede. Quando pequenos, a ausência da fala não atrapalha a livre expressão do bebê, ninguém o reprime em sua fase de desenvolvimento, por que então nos é limitada essa expressão das emoções com o decorrer dos anos?

A arte estimula a criatividade, a expressão artística relaciona-se diretamente com a imaginação, com a capacidade de enxergar além do óbvio, de "pensar fora da caixa"ix e, ao se deparar com problemas, conseguir elaborar alternativas para solucioná-lo. Além disso, nos faz conhecer e admirar a nossa própria cultura, muitas vezes desvalorizada ou esquecida, nos faz entrar em contato com outras culturas, aprendendo a valorizá-las também e respeitá-las ainda que diferentes das nossas, nos ampliando como indivíduo e sociedade.

Diferentemente dos animais, que quando adestrados e ensinados a fazer coisas novas como sentar, dar a pata e etc, recebem em troca comida, e caso não o faça, não a recebe, o nosso processo de aprendizagem não se baseia na sobrevivência, somos movimentados e movimentadas pela necessidade de dar significado às coisas, à vida. "Esta é então a radical diferença entre o homem ${ }^{x}$ e o animal: a consciência reflexiva, simbólica. A palavra é o primeiro elemento transformador do mundo e que se vale o ser humano” (DUARTE JÚNIOR, 2019, $s / p)$.

Através da palavra é que chegamos à consciência reflexiva e simbólica onde podemos compreender coisas que normalmente não estão ao alcance, longe de nossos sentidos como sentimentos, noções de tempo e espaços diferentes do aqui e agora. Na urgência de buscar significados, nossa mente acaba sendo seletiva e aprendendo apenas o que é entendido como necessário à nossa existência.

Por isso uma educação que apenas pretenda transmitir significados que estão distantes da vida concreta dos educandos, não produz aprendizagem alguma. É necessário que os conceitos (símbolos) estejam em conexão com as experiências dos indivíduos. Voltamos assim à dialética entre o sentir (vivenciar) e o simbolizar. (DUARTE JÚNIOR, 2019, s/p)

As palavras são apenas um código universalizado e ainda que se transforme, conforme a cultura local (como as diferentes línguas de diversos países, por exemplo), tem como finalidade facilitar a comunicação. Vejamos que, aliada à comunicação temos a expressão e que, embora andem juntas, são dimensões distintas. A comunicação faz com que a mensagem a ser transmitida seja recebida e compreendida sem ambiguidades ou ruídos, ao contrário da 


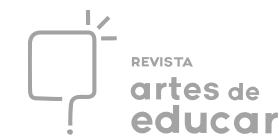

expressão, onde a manifestação de sentimentos é o ponto principal, tornando a transmissão da mensagem muitas das vezes ambígua dependendo da interpretação de quem a recebe.

Voltamos assim para o processo de aprendizagem. Para que realmente se aprenda algo temos que sentir (vivenciar) e simbolizar, muitas vezes as palavras e a comunicação não nos bastam, nossa vivencia é regada de sentimentos, emoções e afetos. Por que então o ensino nos deve ser passado através dos símbolos linguísticos e apenas eles?

Como o pesquisador Duarte aponta, se "os símbolos linguísticos são incapazes de nos apresentar integralmente os sentimentos, a arte surge como uma tentativa de fazêe-lo" (DUARTE JÚNIOR, 2019, s/p). A arte então desperta no indivíduo uma maior atenção no processo de sentir, ao contrário, do atual ambiente escolar que enfatiza como relevante aquilo que é compreendido racionalmente, de forma objetiva, sem considerar as vivências e experiências individuais, afastando o processo de ensino da realidade e dificultando o entendimento.

Sem a criatividade influenciada pela arte não criaríamos e não faríamos novas descobertas. Formaríamos indivíduos sem criatividade e capacidade de crítica, pois aceitariam o obvio sem questioná-lo. É por isso que abordamos na presente pesquisa a importância do uso da arte no ensino fundamental, onde a formação do indivíduo está em seu início. "Uma educação só se torna viva quando se carrega durante algum tempo, num plano subjacente, o conteúdo recebido, para depois fazê-lo aflorar novamente” (STEINER, 1919, p. 27). O pensamento steineriano e a pedagogia Waldorf têm muito a contribuir para a construção de uma escola humanizada, onde a ludicidade é a base do ensino, sobretudo de artes.

\section{Pedagogia Waldorf}

A Pedagogia Waldorf compreende que o ser humano desenvolve-se a cada sete anos. A educação, no entanto, ocorre nos três primeiros setênios, ou nos 21 primeiros anos de vida. No primeiro setênio (0-7 anos) o corpo etérico constitui o elemento mais importante. Nessa fase a criança é como um grande órgão sensório extremamente permeável, absorvendo tudo que a circunda: emoções, caráter, sentimentos. Inconscientemente a criança imita o que vê e sente. É um período que exige intensa atividade física pois ocorre o desenvolvimento físico.

No segundo setênio (7-14 anos) o foco torna-se o funcionamento psicoemocional, o corpo astral. $\mathrm{O}$ trabalho artístico existente em toda a pedagogia Waldorf torna-se mais intensa nesse setênio, pois é nele que estão ligados os sentimentos, a fantasia e a emotividade. 
No terceiro setênio (14-21 anos) desenvolve-se a autonomia, e as energias liberadas voltam-se para o despertar das forças do pensar lógico, abstrato e conceitual do indivíduo, onde é desabrochada a individualidade do educando e da educanda (ANDRADE E SILVA, 2015).

\section{O lúdico como forma de ensino}

A ludicidade é primeiramente relacionada ao jogo, à brincadeira e coisas consideradas não "sérias", por ligar-se juntamente à infantilidade. Logo, ao falar sobre uma educação lúdica pode-se ouvir muitas opiniões contrárias ou equivocadas a ela. Em uma tentativa de educar ludicamente, comumente se observa a realização de brincadeiras descontextualizadas em sala de aula sem objetivos definidos.

Para Cipriano Luckesi (2005) ludicidade é uma experiência plena, um estado interno do sujeito, onde o pensar, sentir e fazer caminham juntos. Sendo assim, embora seja vivenciada coletivamente, a ludicidade é interna e única em cada indivíduo. Andrade e Silva (2015) definem educação lúdica como sendo

[...] aquela que, transcendendo o viés estritamente racionalista que tem caracterizado a educação e orientando-se para o desenvolvimento cognitivo, emocional, ético, criativo físico do educando como um ser humano multidimensional, compromete-se com a promoção de aprendizagens significativas que possam envolver o estudante por inteiro, propiciando, assim, a integração harmônica do seu pensar/sentir/fazer. (ANDRADE E SILVA, 2015, p. 107)

Com o lúdico dá-se ao discente a oportunidade de aprender se divertindo, experimentando, descobrindo, e assim, como em uma brincadeira, o aprendizado torna-se prazeroso. A educação lúdica é base estrutural da pedagogia Waldorf, criada por Rudolf Steiner ${ }^{\mathrm{xi}}$

\section{Procedimentos artísticos aplicados ao ensino Waldorf}

Ao contrário de ensinos conservadores e tradicionais, a pedagogia Waldorf busca a autenticidade e independência do ser humano (não só estudante, pois essa autonomia deve se estender além do âmbito escolar) pois afirma que 
[...] desde o berço, o homem moderno está acostumado a uma total passividade mental: os meios de massa lhe servem notícias, divertimentos, slogans prontos; ele vive em apartamentos sem personalidade, em meio a moveis e objetos fabricados em série; as imagens que o circundam (graças à publicidade), as opiniões que ouve, tudo isso o transforma num mero consumidor cuja única iniciativa consiste, a rigor, em escolher entre várias opções igualmente prontas. Sendo solicitado só de fora, sem fantasia nem engajamento próprios, com o pensar reduzido a um raciocínio mecanizado (pelo cientismo que culmina no computador), sua criatividade acaba sendo totalmente atrofiada. (LANZ, 1986. p. 66)

Baseando-se nesta autenticidade e autonomia do indivíduo, a comunidade docente deve conhecer a comunidade estudantil, dosar e individualizar sua forma e intensidade de ensino. Cada discente é único, e existem

[...] alunos [e alunas] cuja fantasia é rica: em casos especiais, chegam a ser atormentados por suas imagens e representações mentais. Para estes, trabalhos manuais, canto, pintura, desenhos geométricos são uma terapia eficaz. E há os outros, de fantasia pobre: estes serão incentivados pela obrigação de observar, de ler e pela prática de música instrumental. (LANZ, 1986, p. 77.)

O corpo docente deve estar presente integralmente em suas aulas para que possa manter os(as) discentes presentes e alertas, despertar a curiosidade destes(as) é um importante recurso utilizado nas escolas Waldorf, pois assim as alunas e os alunos despertam o interesse em aprender e buscar cada vez mais, não aceitando somente o que lhe foi imposto.

Além da criatividade estimulada, trabalha-se muito com a vivência. Tornam os assuntos compreensíveis e "palpáveis", pois através da vivência alargam-se os horizontes e enriquecem a formação do corpo discente. "Pela mesma razão, as artes, os trabalhos manuais e artesanais ocupam na pedagogia Waldorf um lugar de destaque” (LANZ, 1986, p. 84). A juventude ao entrar em contato com atividades primárias da humanidade (fiar, tecer, pintar, esculpir, etc.) agrega respeito ao trabalho manual, sensibilidade pela qualidade do objeto ou da atividade realizada, além de trabalhar perseverança e capricho.

As artes, de forma geral, possuem grande importância na pedagogia Waldorf, e são adaptadas à faixa etária de cada classe e ao que é ensinado nas demais matérias. As obras feitas são compartilhadas em exposições, festas e outras oportunidades, dando a estudantes a sensação da obra participando de um contexto amplo, dando a oportunidade de aprender a criticar e também ouvir críticas sobre sua produção.

Em relação à música, é dada uma ênfase ao canto e a música instrumental, onde todo corpo discente aprende a tocar flauta doce desde o primeiro ano. 
A função social da música, no contexto Waldorf, não é a servidão ao mercado da indústria cultural, tampouco ser uma réplica da mídia e da vitrine do sucesso. (...) O papel da música, além da inclusão de todos os integrantes da classe, é a participação solidária onde se pensa, sente e se faz junto com o outro, esperando pelo próximo. (JUNIOR, MARIN, 2012, p. 25)

Quanto às práticas corporais trabalha-se a eurritmia, que, como arte, busca pesquisar o movimento da linguagem poética e da música, como ele ocorre na fala e no desenvolvimento dos sons com todo o sentimento e conteúdo expresso pelo poeta ou compositor.

Esse elemento artístico-plástico da fala e da música é transposto para o espaço cênico através do movimento coreográfico, complementado pelas cores das indumentárias e da iluminação. Simultaneamente com recitação ou música ao vivo a Eurritmia dança, assim, o desenvolvimento dos sons de poesias e músicas, em toda sua complexidade. (BARRETO, 1998, p. 1)

A eurritmia é uma arte, mas existem também a eurritmia pedagógica, onde trabalha-se harmonia e coordenação, e a eurritmia curativa, que atua terapeuticamente em enfermidades físicas e psíquicas. Em ambos os casos, atua diretamente sobre os corpos superiores do ser humano.

\section{A arte-educação na prática}

Um modelo de uso da arte-educação são as escolas de ensino Waldorf. Inicialmente é preciso entender que nesta pedagogia procura-se um equilíbrio entre o pensar e o sentir. Trabalhando esse caminho juntamente com o processo cognitivo, resulta-se em uma educação da vontade, o querer, o desejo pelo aprendizado.

Esta educação se faz a partir da harmonização do sentir e do entendimento do homem trimembrado ${ }^{\text {xii }}$ considerado por Steiner como um ser que percebe o mundo através dos seus órgãos dos sentidos. (ROMANELLI, 2016, p. 181)

Através desta metodologia, estudantes passam não somente a receber o conteúdo de forma passiva e sim a vivenciá-lo, através do uso de imagens e da fantasia os conhecimentos vão sendo significados e compreendidos de forma ampla e inter-relacionada. A educação iniciase com o despertar da curiosidade para aquilo que será aprendido, a isso se chama educação da vontade, o querer, a necessidade de aprender. Segundo Steiner, 
Desde o início teremos de atribuir grande valor ao cultivo do lado artístico na criança. $\mathrm{O}$ elemento artístico atua de modo muito especial sobre a natureza volitiva ${ }^{\text {xiii }}$ do ser humano. Por meio dele penetramos em algo que está relacionado com o homem todo, enquanto o que se relaciona com o convencional refere-se apenas ao homem-cabeça. (STEINER, 1919, p. 5)

A capacidade volitiva presente nesse ensino, confere ao educando o estimulo necessário para que ele tenha curiosidade em aprender. O querer aprender, buscar e pesquisar para se aprofundar no assunto, mergulhar nele de forma geral. Isso certifica o completo aprendizado, aquele no qual encontramos significado em aprender. Nesta visão:

Eis nossa tarefa quanto ao método: solicitar sempre o ser humano por inteiro. Não conseguiríamos fazê-lo se não focalizássemos o desenvolvimento de uma sensibilidade artística inerente ao homem. Com isto faremos com que mais tarde a pessoa se incline, com todo o seu ser, a possuir um interesse pelo mundo. (STEINER, 1919, p. 6)

Dessa forma, desenvolvendo a sensibilidade artística desenvolve-se também o raciocínio crítico. O interesse em buscar novos conhecimentos reflete em seres curiosos e com potencial criativo. A exemplificação do uso da arte através da metodologia Waldorf tem como finalidade demonstrar exemplos concretos de sua funcionalidade, entretanto, não devemos restringi-la apenas a isto. A antroposofia, base do estudo Waldorf, é considerada um método de conhecimento que engloba muito além do que os aspectos aqui retratados, abrangendo conhecimentos da natureza, ser humano e universo.

Apesar de seu custo e de normalmente serem estudos particulares, existem projetos já em andamento de escolas públicas nessa vertente. O Instituto Ruth Salles ${ }^{\text {xiv }}$ atua impulsionando a criação de novas escolas baseadas na Pedagogia Waldorf, especialmente na rede pública, através de divulgação da pedagogia e assessoria a organizações e governos ${ }^{\mathrm{xv}}$.

Nesse processo, já foram instauradas onze escolas públicas: Escola Municipal Comunitária do Vale de Luz - Nova Friburgo RJ; Escola Municipal Cecília Meireles - Nova Friburgo RJ; Escola Municipal Araucária - Camanducaia MG; Escola Murundu - Palmeiras BA; Escola Waldorf Anael - Várzea da Roça BA; Escola Casa da Mata - Mata de São João BA; EMEI Dr. José Calumby Filho - Aracaju SE; EMEF José Souza de Jesus - Aracaju SE; CREI Flor de Araçá - Conde PB; Centro de Educação Infantil (CEI) 316 Norte - Brasília DF; EMEB Manoel Aníbal Marcondes - Jundiaí SP.

Em São Paulo existe somente uma escola pública Waldorf, a EMEB Manoel Aníbal Marcondes - "Quintal do Aníbal”, mas a existência destas também em outros estados mostram 
que essa é uma realidade possível e que podemos adotar características desse modelo para a implantação de uma arte-educação efetiva nas escolas públicas. Através do enfoque artístico da pedagogia steineriana podemos estimular a criatividade, a imaginação, o interesse no saber e assim elevar a qualidade de ensino das escolas públicas brasileiras.

Uma pesquisa realizada pelo Instituto Ruth Salles em oito escolas públicas que adotaram a pedagogia Waldorf e três iniciativas Waldorf na rede pública que foram descontinuadas ${ }^{\mathrm{xvi}}$ apontou, dentre tantas outras coisas, alguns pontos positivos que surgiram através dessa pedagogia humanizadora.

A Escola Araucária, por ser a única na região há mais de 40 anos, é um ótimo exemplo de como uma escola bem estruturada e com uma pedagogia humanizada, emancipadora e focada no desenvolvimento integral do ser humano, tem o poder de transformar toda uma comunidade nos aspectos culturais, sociais e econômicos. Numa região onde quase todos eram analfabetos e viviam de agricultura de subsistência, hoje saem jovens que já seguiram carreiras como Medicina, Direito, Enfermagem, Pedagogia, Artes Cênicas, Música, Arquitetura, Zootecnia, Agronomia, Administração, Turismo e Hotelaria entre outras profissões. (SALLES \& FONSECA, 2019, p. 133)

Esse relato, vindo diretamente de uma iniciativa Waldorf inserida na rede pública, nos mostra que essa é uma realidade possível e que ela tem um grande poder transformador não só da comunidade local, transformando alunos e suas famílias, mas que também contribui formando alunos com grande capacidade de melhorar a vida da sociedade de forma geral.

\section{A arte como um caminho}

Diante de todos os apontamentos levantados durante a pesquisa, pôde-se perceber que a arte ainda sofre preconceitos principalmente quanto ao seu ensino. As escolas públicas, principalmente estaduais, ainda têm seu ensino defasado com desvalorização de profissionais, baixo salário, pouco investimento, espaços e materiais. Uma pesquisa feita, em plena pandemia, entre abril e maio de 2020 pela Fundação Carlos Chagas aponta que para mais de $65 \%$ das respondentes, o trabalho pedagógico mudou e aumentou. Atividades como planejar/preparar aulas com novos recursos/ferramentas aumentou em $80 \%$ enquanto atividades menos comuns na rotina docente como escrever/responder e-mail/WhatsApp/SMS, muitas vezes esclarecendo dúvidas e dando suporte aos alunos, subiu em 91,4\% e, apesar dos esforços, 49,3\% dos docentes acreditam que somente parte dos(as) estudantes consegue realizar as atividades. 
Todos esses dados apontam para problemas já enfrentados antes da pandemia, mas que ficaram explícitos com o ensino EAD: desvalorização da profissão docente, desigualdade social, racismo e disparidades educacionais foram algumas que mais se destacaram.

Além disso, todos esses fatores contribuem para mais dificuldades no ensino, uma vez que, docentes e estudantes desmotivados, estressados(as), sem os materiais e apoio necessários acabam com sua saúde mental abalada, ansiosos(as) e preocupados(as), gerando cada vez mais um desgaste no processo de ensino-aprendizagem.

Diante dessa perspectiva demonstramos algumas possibilidades de se trabalhar a arte nas escolas públicas, dentre elas, a pedagogia Waldorf. Em uma entrevista realizada pelo Instituto Ruth Salles, Paulo do Eirado Dias Filho ${ }^{\text {xvii }}$ diz que

[...] a Pedagogia Waldorf pode ser muito bem implantada dentro das redes públicas e a gente tem resultados maravilhosos e eu espero que se consolide mais, até para demonstrar, sob todas as avaliações e todos os testes necessários, de que ali de fato tem uma proposta educacional muito séria, muito robusta e muito própria para a educação pública. (INSTITUTO RUTH SALLES apud FILHO, 2019, p. 70)

O Instituto Ruth Salles instaurou um curso de formação continuada que ensina alguns elementos da Pedagogia Waldorf para professores da rede pública, do ensino infantil e fundamental I em cinco municípios paulistas: São Paulo, Itapecerica da Serra, Embu Guaçu, Espírito Santo do Turvo e Timburi. Através dele, surgiram alguns pontos importantes, tais como:

1- Elementos da Pedagogia Waldorf podem enriquecer e humanizar a educação nas escolas públicas, desde que os professores tenham interesse em conhecê-la e oportunidade de vivenciar seus benefícios com seus alunos. 2 É difícil para professores realizarem um trabalho muito diferente dos demais em uma escola pública, sem terem incentivo, formação continuada e apoio de outros colegas e da direção da escola. Sem isso, sua iniciativa está fadada a perder força. (INSTITUTO RUTH SALLES, 2019, p. 127)

Através desses relatos e de todos os pontos apresentados nessa pesquisa pudemos perceber que há sim formas diferentes de pensar e ensinar a arte nas redes públicas e que elas são possíveis e cabíveis dentro dessa realidade, incentivando o interesse das(os) professoras(es) ao campo das artes e realizando investimento e incentivo dos órgãos superiores, do contrátio, qualquer forma de inovação está destinada ao fracasso. Para isso, é necessário uma abertura do corpo docente das escolas e da sociedade de forma geral para essas novas visões e um maior incentivo do governo e das próprias escolas. 


\section{REFERENCIAS}

ANDRADE E SILVA, Dulciene Anjos de. Educação e ludicidade: um diálogo com a Pedagogia Waldorf. Educar em Revista, Curitiba, UFPR, n. 56, jun. 2015.

BARRETO, Marília. Eurritmia. Sociedade Antroposófica no Brasil. 1998. Disponível em: http://www.sab.org.br/euritmia/ . Acesso em: 17 set. 2020.

BARBOSA, Ana Mae Tavares Bastos. Arte-educação no Brasil: das origens ao modernismo. São Paulo: Ed. Perspectiva, 1978.

BARBOSA, Ana Mae Tavares Bastos. Arte-Educação no Brasil: realidade hoje e expectativas futuras. Estudos avançados, São Paulo, v. 3, n. 7, p. 170-182, 1989.

BRASIL. Ministério da educação. Base Nacional Comum Curricular (BNCC), Brasil, 2018. Coleção das leis do império do Brasil. Rio de Janeiro, Tomo XVIII, parte II, 1855.

. Constituição (1988). Constituição da República Federativa do Brasil. Brasília, DF: Senado, 1988.

- Instituto Nacional de Estudos e Pesquisas Educacionais Anísio Teixeira Estatísticas dos professores no Brasil. Brasília: INEP, 2004. Disponível em: http://portal.inep.gov.br/documents/186968/484154/Estat\%C3\%ADsticas+dos+professores+n o+Brasil/2cfab3f2-3221-4494-9f7e-63ae08c154e1 ?version=1.1. Acesso em: 04 set. 2020.

DUARTE JÚNIOR, João Francisco. Por que arte-educação? Campinas: Papirus, 2019. ePub.

JUNIOR, Jonas Bach; MARIN, Andreia A. A educação estética na pedagogia Waldorf: o imaginário e a paisagem interior. Interfaces da Educação, Paranaíba, v. 3, ed. 8, p. 19-34, 2012.

KILOMBA, Grada. Memórias de plantação: Episódios de racismo cotidiano. Rio de Janeiro: Editora Cobogó, 2019.

LANZ, Rudolf. A pedagogia Waldorf: caminho para um ensino mais humano. 4 ed. São Paulo: Editora Antroposófica, 1986.

MÄDER, Maria de Lourdes Pereira et al. A Arte como processo na educação. Rio de Janeiro: FUNARTE, 1981.

ROMANELLI, Rosely Aparecida. Procedimentos Artísticos no Ensino Waldorf. Revista da Faculdade de Educação. Cáceres, UNEMAT, Vol. 2, jul/dez. 2016.

SALLES, Rubens; FONSECA, Rosineia. A Pedagogia Waldorf na escola pública: histórico desafios - perspectivas. Instituto Ruth Salles, [s. l.], 18 mar. 2019. Disponível em: https://www.institutoruthsalles.com.br/wp-content/uploads/2020/03/A-Pedagogia-Waldorfna-escola-p\%C3\%BAblica.pdf . Acesso em: 2 out. 2020. 
STEINER, Rudolf. A arte da educação II: metodologia e didática no ensino Waldorf. Conferência, $\quad$ Stuttgart, $1919 . \quad$ Disponível em http://culturadigital.br/gepepi/files/2011/02/Steiner_-

A arte da educa\%C3\%A7\%C3\%A3o II1.pdf. Acesso em: 26 dez. 2019.

TODOS PELA EDUCAÇÃO. Ensino a distância na educação básica frente à pandemia da

COVID-19. Nota técnica, Brasil, Abril 2020. Disponível em: https://www.todospelaeducacao.org.br/_uploads/_posts/425.pdf?1730332266=\&utm_source= conteudo-nota\&utm medium=hiperlink-download. Acesso em: 10 set. 2020.

\footnotetext{
${ }^{i}$ Arte-educadora, dançarina e artista visual. Licencianda em Artes pelo UNISAGRADO (2018-2021). E-mail: gabrielamcardoso@hotmail.com. ORCID: https://orcid.org/0000-0003-3125-5084.

ii Ator-Pesquisador. Doutorando no Programa de Pós-Graduação em Artes da Cena pela UNICAMP. Mestre em Artes da Cena e Graduado em Artes Cênicas, todos pela UNICAMP. Professor do Bacharelado em Teatro e Licenciatura em Artes no UNISAGRADO. Ator e Produtor no TEATROdaPASSAGEM - Núcleo de Teatro Performativo. E-mail: ronaldoteatroprofessor@gmail.com. ORCID: https://orcid.org/0000-0002-0469-7269.

iii A Semana de Arte Moderna, também chamada de "Semana de 22", aconteceu no Teatro Municipal de São Paulo, de 11 a 18 de fevereiro de 1922. Foi um encontro de novas ideias estéticas, que mudaram a arte e a literatura brasileiras.

iv Em 1971 o 'Movimento Escolinhas de Arte' estava difundido por todo o país com 32 Escolinhas, a maioria delas particulares, oferecendo cursos de artes para crianças e adolescentes e cursos de arte-educação para professores e artistas (BARBOSA, 1989, p. 1).

${ }^{v}$ Napoleão Bonaparte (1769-1821) foi um militar, líder político e imperador dos franceses.

vi Joaquim Lebreton, crítico de arte, fundador da "Escola Real de ciências, artes e ofícios" e idealizador e fundador da "Missão Artística" de 1816.

vii A Missão Artística Francesa foi um grupo de artistas e artífices franceses que, deslocando-se para o Brasil no início do século XIX, revolucionou o panorama das Belas-Artes no país introduzindo o sistema de ensino superior acadêmico e fortalecendo o Neoclassicismo que ali estava iniciando seu aparecimento.

viii É a expressão inglesa que significa "poucos felizes" e que designa a elite intelectual.

${ }^{\text {ix }}$ A expressão 'pensar fora da caixa' pode ser relacionada a indicação de um pensamento novo. Alguém que consegue visualizar um fator por diversos ângulos, ter um pensamento criativo.

x Lê-se "homem" como sinônimo de ser humano em todas as referências que a essa palavra se relacionarem.

${ }^{\text {xi }}$ Rudolf Steiner, de origem austríaca, foi um filósofo, educador, artista e esoterista fundador da antroposofia e da pedagogia Waldorf.

xii A cosmovisão da pedagogia Waldorf considera o ser humano como uma entidade formada por corpo, alma e espirito. Os três sistemas se relacionam, respectivamente, com as três forças da alma humana: pensar, sentir e querer.

xiii $\mathrm{O}$ adjetivo volitivo provém do termo latim volo, que significa "quero/querer/vontade".

xiv O Instituto Ruth Salles nasceu a partir da experiência do Instituto Artesocial, acumulada desde 2002, e inspirado pelo trabalho da poetisa, dramaturga e escritora Ruth Salles. Durante vários anos realizaram o projeto Dom da Palavra, ensinando elementos da Pedagogia Waldorf para professores da rede pública, assim como vários projetos editoriais.

${ }^{x v}$ Mais informações podem ser encontradas no site do Instituto: http://www.institutoruthsalles.com.br/quemsomos/o-instituto/.

xvi EMEF Antônio Gonçalves das Neves - Espírito Santo do Turvo SP; Escola Jardim da Manga - Ubá MG; Escola Saber do Campo - Ibicoara BA

xvii Paulo do Eirado Dias Filho, um dos coordenadores do Instituto Social Micael, de Aracaju SE.
}

Revista Interinstitucional Artes de Educar. Rio de Janeiro, V. 7, N. 1 - pág. 670-685 janeiroabril de 2021: "Pedagogias Vitais: Corpo, Desejo e Educação" DOI: 10.12957/riae.2021.55358 